\title{
Facilitative Glucose Transporters: Regulatory Mechanisms and Dysregulation in Diabetes
}

\author{
Barbara B. Kahn
}

The Charles A. Dana Research Institute and Harvard Thorndike Laboratory, Department of Medicine, Beth Israel Hospital and Harvard Medical School, Boston, Massachusetts 02215

\section{Introduction}

Maintenance of normal glucose homeostasis results from the precise orchestration of three processes: glucose absorption via the gut, production by the liver, and utilization by nearly all tissues in the body. In the fasting state, most of glucose utilization is by brain and is independent of insulin. Glucose levels are maintained during a fast by the tightly regulated release of glucose from the liver. Postprandially, increased insulin levels promote enhanced glucose uptake, metabolism, and storage in muscle and adipose cells, with skeletal muscle quantitatively most important. The increment in insulin and decrement in glucagon concentrations in the portal circulation inhibit hepatic glucose production. States such as diabetes and obesity are characterized by resistance to the effect of insulin on both the stimulation of peripheral glucose utilization as well as the inhibition of hepatic glucose production. Diabetes is further marked by inadequate insulin secretion to meet the increased demands resulting from peripheral insulin resistance.

In mammalian cells, glucose is not freely permeable across the lipid bilayer but enters by facilitated diffusion, a process in which specific integral membrane proteins passively transport glucose down a concentration gradient. Glucose can also be concentrated in epithelial cells of the intestine and the proximal tubule of the kidney by an active process in which $\mathrm{Na}^{+} / \mathrm{glu}-$ cose cotransporters (reviewed in 1) utilize the electrochemical potential of $\mathrm{Na}^{+}$as an energy source. Molecular cloning studies over the last seven years have revealed a family of facilitated diffusion glucose transporter proteins which are structurally related but are encoded by distinct genes that are expressed in a tissue specific manner (reviewed in 2-4) (Table I). These are structurally and genetically distinct from the $\mathrm{Na}^{+}$-linked glucose cotransporters but bear considerable sequence homology with sugar transporters in bacteria, yeast, and protozoa (3). Recent studies have begun to unravel the mechanisms by which facilitated diffusion transporters participate in the regulation of glucose utilization in various tissues. This Perspectives will discuss evidence that altered expression, localization, and/ or function of facilitative glucose transporters may contribute to the pathogenesis of diseases such as diabetes.

Barbara B. Kahn, M. D., Diabetes Unit, Beth Israel Hospital, 330 Brookline Avenue, Boston, MA 02215.

Received for publication 12 November 1991 and in revised form 21 January 1992.

J. Clin. Invest.

(C) The American Society for Clinical Investigation, Inc. 0021-9738/92/05/1367/08 \$2.00

Volume 89, May 1992, 1367-1374
Gene family of facilitated diffusion glucose transporters

Five facilitated diffusion glucose transporter genes and one pseudogene have been identified (Table I) and a nomenclature refers to them in the order of cloning. GLUT1, cloned in 1985, is widely expressed both in tissues in which glucose transport is acutely stimulated by insulin and in non-insulin-responsive tissues (2-4). It is present at high levels in the blood-brain barrier and it is the human erythrocyte glucose transporter. GLUT3 is also widely expressed and is present at highest levels in brain. The role of GLUT1 and GLUT3 in different areas of brain is an active focus of investigation. In contrast, the tissue distributions of GLUT2 and GLUT4 are much more restricted. GLUT2 is present primarily in liver, kidney, intestine (basolateral membrane), and pancreatic $\beta$ cells (2-4). With the exception of the latter, these are all tissues in which net release of glucose can occur. GLUT4 is unique in that it is expressed primarily in tissues in which glucose transport is rapidly and markedly enhanced in response to insulin, i.e., adipose cells, cardiac and skeletal muscle (2-4). Its expression and function are modulated by physiological factors (reviewed in 5 , Tables II and III) and its regulation may be a major determinant of insulin responsiveness in adipose cells and muscle (see below). GLUT5 is expressed primarily in small intestine (3). GLUT6 (renamed GLUT3P1) is a pseudogene which is not translated into a functional protein due to the presence of multiple translation termination codons and frameshifts (3). The structures and biochemical characteristics of these transporter isoforms have recently been reviewed (2-4) and will be discussed here only in the context of the major focus of this review: the regulation of these transporters in vivo and their dysregulation in disease states.

\section{Mechanisms for regulation of glucose transport in different tissues}

Kinetic characteristics of different transporter isoforms. Transport rate is determined by both the $V_{\max }$, maximal velocity, and the $K_{\mathrm{m}}$ which inversely reflects the affinity for glucose. Reports of the $K_{\mathrm{m}}$ of GLUT1 vary widely (2-20 mM) and measurements are complicated by accelerated exchange, a phenomenon characterized by simultaneous changes in $V_{\max }$ and $K_{\mathrm{m}}(2,6,7)$. Since the $K_{\mathrm{m}}$ of GLUT4 $(2-10 \mathrm{mM})$ is in the range of physiologic glucose concentrations, this transporter can be nearly saturated in vivo and transport can be rate limiting for glucose metabolism in tissues where GLUT4 is the major transporter, i.e., muscle and adipose cells. In contrast, GLUT2 has a $K_{\mathrm{m}}$ of $\sim 20-66 \mathrm{mM}(2,6)$. Thus, its capacity to transport glucose can increase proportionally with increases in extracellular or intracellular glucose over a range of physiological glucose concentrations and transport does not become rate limiting in tissues where it is the predominant transporter, i.e., liver. 


\begin{tabular}{|c|c|c|c|}
\hline Gene & Nomenclature & Major sites of expression & $\begin{array}{l}\text { Regulatory } \\
\text { features }\end{array}$ \\
\hline \multicolumn{4}{|l|}{ Facilitative } \\
\hline GLUT1 & Erythrocyte & $\begin{array}{l}\text { Many tissues; high levels in human } \\
\text { erythrocytes, brain, blood-brain } \\
\text { barrier, placenta, kidney, colon, } \\
\text { fetal tissues }\end{array}$ & $\begin{array}{l}\text { Expression regulated by insulin, growth factors, } \\
\text { oncogenes, glucocorticoids, cAMP, protein } \\
\text { kinase } \mathrm{C} \text {, glucose, sulfonylureas (review 5) }\end{array}$ \\
\hline GLUT2 & Liver & $\begin{array}{l}\text { Liver, pancreatic } \beta \text { cells, kidney, } \\
\text { small intestine }\end{array}$ & $\begin{array}{l}\text { Potential role in "glucose sensing" for insulin } \\
\text { secretion (review 30) }\end{array}$ \\
\hline GLUT3 & Brain & $\begin{array}{l}\text { Many tissues; high levels in brain, } \\
\text { placenta, kidney }\end{array}$ & Developmentally disappears in muscle \\
\hline GLUT4 & Muscle/Fat & $\begin{array}{l}\text { Skeletal muscle, heart, white adipose } \\
\text { cells, brown fat }\end{array}$ & $\begin{array}{l}\text { Expression is more highly regulated in adipose } \\
\text { cells than in muscle. Regulation of function } \\
\text { is important in muscle in insulin-resistant } \\
\text { states. }\end{array}$ \\
\hline GLUT5 & Small intestine & Small intestine & \\
\hline GLUT6 (GLUT3P1) & Pseudogene & & \\
\hline \multicolumn{4}{|l|}{ Concentrative } \\
\hline SGLT1 & $\begin{array}{l}\mathrm{Na}^{+} / \text {glucose } \\
\text { cotransporter }\end{array}$ & Small intestine-brush border & \\
\hline
\end{tabular}

The rate at which different transporter isoforms transport glucose may also depend on their intrinsic activity or glucose turnover number which is a determinant of $V_{\max }$. This parameter has been difficult to determine with transporters in their normal tissue context since many tissues express more than one transporter isoform. The problem has been approached by expressing individual transporter isoforms in Xenopus laevis oocytes but not all isoforms insert efficiently in the oocyte plasma membrane and quantitation of the number in the plasma membrane is difficult $(6,7)$. Interpretation is further limited by the fact that elements of the native tissue milieu which may modulate transporter intrinsic activity may not be present in the oocyte.

Regional expression of glucose transporters within a tissue: functional significance. The localized expression of different transporter isoforms within a tissue suggests that different isoforms may be suited to different functions. For example, GLUT2 in the kidney is expressed in gluconeogenic cells while GLUT1 expression correlates with the glycolytic activity of different nephron segments (8). In the liver, all hepatocytes express GLUT2 while GLUT1 expression is limited to a single row of cells surrounding the hepatic vein under normal metabolic conditions (9). With metabolic perturbations such as fasting or diabetes, additional perivenous hepatocytes are "recruited" to express GLUT1 (9); the physiological significance of this is under investigation.

Although both GLUT1 and GLUT4 are expressed in adipose cells (10-15) and muscle $(10,16-18)$, their localization within these tissues differs. GLUT4 is much more abundant in rat adipose cells $(14,15)$, soleus muscle, and heart (16) than GLUT1. In contrast to adipose cells, in skeletal muscle GLUT1 and GLUT4 appear to be primarily in different cell types. Localization studies with fluorescently labeled antibodies indicate that GLUT1 is present in very low abundance in skeletal muscle fibers and in high abundance in the perineurial sheath $(17,18)$. On the other hand, GLUT4 localizes in the sarcolemma and within the muscle fiber (18). Electron microscopy studies of heart muscle demonstrate GLUT4 in a tubular vesicular compartment associated with the trans-Golgi region as well as in the sarcolemma (19). Such studies have been unable to detect GLUT1 in muscle fibers (J. Slot, personal communication). Thus, the function of GLUT1 in muscle tissue may differ from its role in adipose cells.

The relative abundance of GLUT4 in different muscle fiber types and adipose cells corresponds to the glucose utilization rates in these tissues: brown adipose tissue $>$ heart $>$ red muscle $>$ white muscle and white adipose tissue (20). Within skeletal muscle GLUT4 expression varies with muscle fiber type and is highest in muscles enriched in type IIa (oxidative/glycolytic) fibers, intermediate in muscles enriched in type I (oxidative) fibers, and lowest in muscles enriched in type IIb (glycolytic) fibers (21). One study found no correlation between GLUT4 protein content and insulin-stimulated glucose uptake, but significant correlations between GLUT4 protein content and glucose uptake stimulated either by contraction alone or in combination with insulin (21). In human skeletal muscle which is a relatively homogeneous mixture of fiber types, GLUT4 levels correlate inversely with the percent type IIb (glycolytic) fibers (22). These findings are consistent with the level of GLUT4 expression being one important determinant of maximally stimulated glucose transport activity in skeletal muscle.

Subcellular distribution: targeting to different cellular compartments. Targeting of different transporter isoforms to different cellular compartments is another mechanism for regulating transporter function. Thus, although both GLUT1 and GLUT4 polypeptides are present in adipose cells, their subcellular distribution differs importantly. These two transporters probably reside primarily in different intracellular vesicles (14, 23) which may play a role in cellular targeting. In the basal state 
(absence of insulin) GLUT1 transporters are distributed relatively evenly between the plasma membrane and low density microsomal pool whereas GLUT4 transporters are almost entirely in an intracellular pool $(11,20)$. This sequestration of GLUT4 provides a reserve mechanism by which muscle and adipose cells can rapidly and greatly alter glucose utilization in response to hormonal stimulae, especially insulin. In contrast, GLUT2 in liver, pancreatic $\beta$ cells, and the basolateral membranes of intestine and renal tubular epithelium is detectable immunocytochemically only in the plasma membrane. This distribution combined with its inherent high $K_{\mathrm{m}}$ (low affinity for glucose) provides these tissues with the ability to alter the rate of glucose transport over a wide range of ambient glucose concentrations. This transporter participates in both glucose influx and efflux in liver and kidney so these tissues can modulate ambient glucose levels under many metabolic conditions.

Modulation of the level of transporter expression. Expression of various transporter isoforms appears to be regulated at both pretranslational and posttranslational steps. In rat and human adipose cells in states such as fasting or diabetes, decreased insulin-stimulated glucose transport may be due to decreased GLUT4 synthesis due to depressed mRNA levels (1013, 24-26). Refeeding fasted rats or insulin treating diabetic rats increases GLUT4 mRNA levels and restores GLUT4 protein levels compared to control. In contrast, GLUT1 mRNA and protein levels are unaltered with diabetes. However, with insulin treatment GLUT1 mRNA levels in adipose cells increase while GLUT1 protein remains unchanged (11). This suggests posttranscriptional regulation of GLUT1 with insulin treatment and demonstrates divergent regulation of two transporter isoforms within a single cell type.

In skeletal muscle of rats made diabetic by injection of a $\beta$ cell toxin, streptozotocin, levels of GLUT4 mRNA decrease before GLUT4 protein levels fall (18). This indicates a longer half-life of the GLUT4 protein than the mRNA and suggests that at this time in the course of diabetes, posttranscriptional factors are important in regulating GLUT4 levels in muscle. GLUT2 in liver also appears to be regulated mainly posttranscriptionally since GLUT2 mRNA levels are depressed with fasting and diabetes and elevated with refeeding with minimal alteration in GLUT2 protein levels (27). In contrast, in pancreatic $\beta$ cells from several rodent models of diabetes, GLUT2 protein is decreased (28-30). This is one of many demonstrations of tissue specific regulation of the expression of individual glucose transporter isoforms.

Tissue-specific regulation of glucose transporter expression. One of the most important examples of tissue specific regulation of glucose transporters occurs in skeletal muscle and adipose cells of fasted and diabetic rats. Although GLUT4 mRNA and protein levels are markedly decreased in adipose cells (10,

B Insulin Resistant

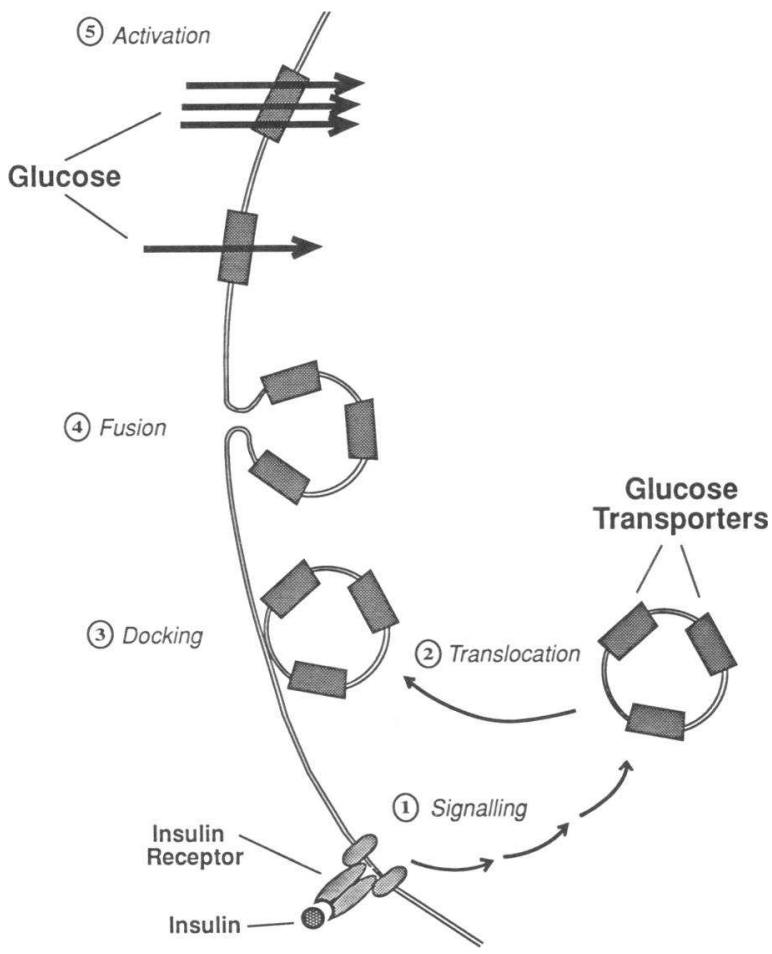

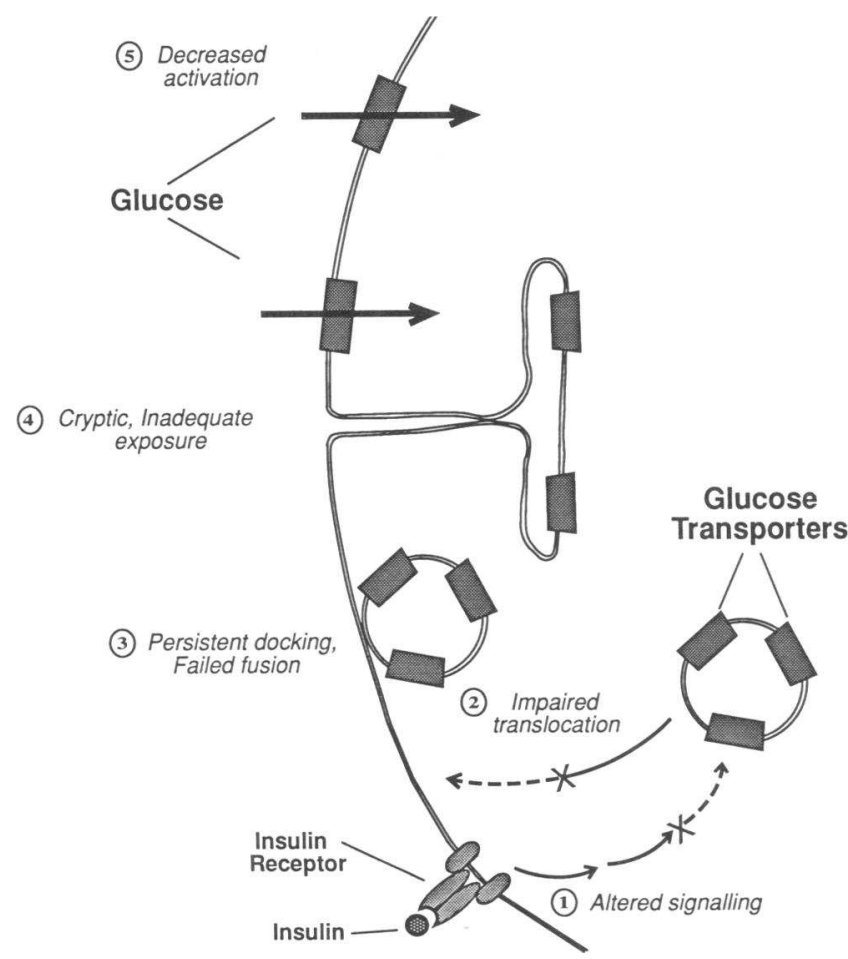

Figure 1. (A) Sequence of events involved in insulin stimulation of glucose transport in muscle and adipose cells: (1) insulin binding to its receptor in the plasma membrane initiates a cascade of signals resulting in (2) the translocation of glucose transporters from an intracellular pool associated with membrane vesicles to the plasma membrane where they (3) dock, (4) fuse, and (5) are further activated ([A] adapted from [44]). (B) Potential functional defects contributing to insulin-resistant glucose transport in muscle in diabetes, obesity, and other insulin-resistant states. Defects may involve (1) deficient signaling, (2) impaired translocation, (3) persistent "docking" without fusion, (4) partial fusion rendering transporters cryptic with inadequate exposure to the extracellular milieu, or (5) reduced activation of transporters. 
Table II. Insulin-stimulated Glucose Transport and GLUT4 Protein Levels in Adipose Cells and Muscle in Altered Metabolic States: Rodent Models

\begin{tabular}{|c|c|c|c|c|}
\hline \multirow[b]{2}{*}{$\begin{array}{l}\text { Metabolic } \\
\text { state }\end{array}$} & \multicolumn{2}{|c|}{ Adipose cells } & \multicolumn{2}{|c|}{ Muscle } \\
\hline & $\begin{array}{l}\text { Glucose } \\
\text { transport* }\end{array}$ & $\begin{array}{l}\text { GLUT4 } \\
\text { protein }\end{array}$ & $\begin{array}{l}\text { Glucose } \\
\text { uptake }^{\ddagger}\end{array}$ & $\begin{array}{l}\text { GLUT4 } \\
\text { protein }\end{array}$ \\
\hline Fasting & $\downarrow$ & $\downarrow(26)$ & $\downarrow$ & $\uparrow(26)$ \\
\hline \multicolumn{5}{|l|}{ Obesity-Dietary } \\
\hline High fat & $\downarrow$ & $\downarrow(74)$ & $\downarrow$ & - \\
\hline High calorie/carbohydrate & $\rightarrow$ & $\rightarrow(74)$ & - & - \\
\hline \multicolumn{5}{|l|}{ Obesity-Genetic } \\
\hline Zucker fa/fa & $\uparrow$ & $\uparrow, \downarrow^{\S}(32,34)$ & $\downarrow$ & $\rightarrow(32,33)$ \\
\hline \multicolumn{5}{|l|}{ Diabetes } \\
\hline Streptozotocin & $\downarrow$ & $\downarrow(10,11,24)$ & $\downarrow$ & $\rightarrow, \downarrow^{\prime \prime}(18,31,37)$ \\
\hline Partial Pancreatectomy & $\downarrow$ & $\downarrow(46)$ & $\downarrow$ & - \\
\hline Genetic db/db & $\downarrow$ & $\rightarrow(49)$ & $\downarrow$ & $\rightarrow(49)$ \\
\hline Insulin-infused normal & $\uparrow$ & $\uparrow(75)$ & $\downarrow(35)$ & - \\
\hline Insulin-treated diabetic & $\uparrow \uparrow$ & $\uparrow(10,11)$ & - & $\rightarrow(18,31)$ \\
\hline Phlorizin-treated diabetic" & $\rightarrow$ & $\downarrow(46)$ & $\rightarrow$ & - \\
\hline Exercise & $\uparrow$ & $\uparrow(76)$ & $\uparrow$ & $\uparrow(64)$ \\
\hline
\end{tabular}

All data are compared to corresponding ad lib. fed, nondiabetic littermates.

* 3-O-methylglucose or 2-deoxyglucose transport was measured in isolated adipose cells after incubation with maximally stimulating concentrations of insulin.

${ }^{\ddagger}$ Glucose uptake into muscle in vivo was measured by euglycemic insulin clamp at maximally stimulating insulin concentrations or insulin tolerance test.

${ }^{8}$ GLUT4 levels are increased initially but decrease at $20 \mathrm{wk}$ of age.

"GLUT4 levels are normal initially but decrease subsequently.

'Phlorizin treatment normalizes blood glucose in diabetic rats without restoring insulin levels.

$\rightarrow$ No change from control levels.

References are for GLUT4 levels. In some cases transport and uptake data are from earlier studies which are reviewed in the designated references.

11, 24-26), GLUT4 protein levels are increased in hindlimb muscle of fasted (26) rats and unaltered initially in muscle of streptozotocin diabetic rats, even when significant insulin resistance is evident in vivo $(18,31)$. Subsequently, levels of GLUT4 decrease in muscle of diabetic rats but much later than in adipose cells, suggesting that in muscle a functional defect in transporters precedes the decrease in gene expression. Within muscle, red fibers are much more susceptible than white fibers to the ultimate effect of diabetes on GLUT4 expression (31). Tissue-specific regulation of GLUT4 is evident not only in insulinopenic models of insulin-resistant glucose uptake but also in models which display metabolic characteristics more similar to human obesity and type II diabetes such as the Zucker fa/fa rat, a model of genetic obesity with endogenous hyperinsulinemia (Table II) (32-34). The mechanisms by which this tissue specific regulation is achieved may involve specific DNA binding proteins.

Cellular mechanisms for hormonal stimulation of glucose transport in adipose cells and muscle

Translocation of glucose transporters. In adipose cells, skeletal muscle, and heart, glucose transport increases rapidly after brief exposure to insulin (reviewed in 35-38). A major mechanism for this increase is the exocytotic-like translocation of glucose transporters from a large intracellular pool associated with specific membrane vesicles $(23,39)$ to the plasma membrane (Fig. $1 A$ ). Both GLUT1 and GLUT4 are translocated to the plasma membrane in response to insulin, but the magnitude of the response differs greatly $(11,20,23)$. Insulin expo- sure of adipose cells results in a marked 10 to 20 -fold increase in GLUT4 in the plasma membrane with a smaller 1.5- to 3-fold increase in GLUT1 $(11,20)$. Electron microscopic studies using immunogold labeling of GLUT4 report a 40 -fold

Table III. Insulin-stimulated Glucose Transport and GLUT4 Protein Levels in Adipose Cells and Muscle from Humans in Altered Metabolic States

\begin{tabular}{|c|c|c|c|c|}
\hline \multirow[b]{2}{*}{$\begin{array}{l}\text { Metabolic } \\
\text { state }\end{array}$} & \multicolumn{2}{|c|}{ Adipose cells } & \multicolumn{2}{|c|}{ Muscle } \\
\hline & $\begin{array}{c}\text { Glucose } \\
\text { transport* }\end{array}$ & $\begin{array}{l}\text { GLUT4 } \\
\text { protein }\end{array}$ & $\begin{array}{l}\text { Glucose } \\
\text { uptake }^{\ddagger}\end{array}$ & $\begin{array}{l}\text { GLUT4 } \\
\text { protein }\end{array}$ \\
\hline Obesity & $\downarrow$ & $\downarrow, \rightarrow^{8}(12,13)$ & $\downarrow$ & $\rightarrow "(59,62)$ \\
\hline NIDDM & $\downarrow$ & $\downarrow \downarrow(12,13)$ & $\downarrow \downarrow$ & $\rightarrow(59,60)$ \\
\hline IDDM & $\downarrow$ & - & $\downarrow$ & $\rightarrow(61)$ \\
\hline Exercise & - & - & $\uparrow$ & $\uparrow(22)$ \\
\hline
\end{tabular}

All data are compared to age-matched, lean, nondiabetic controls. NIDDM muscle data show the same results when also compared to obese nondiabetic controls.

* 3-O-methylglucose transport was measured in isolated adipose cells after incubation with maximally stimulating concentrations of insulin. ${ }^{\ddagger}$ Glucose uptake into muscle in vivo was measured by euglycemic insulin clamp at very high physiologic or maximally stimulating insulin concentrations.

${ }^{8}$ One study (13) found a $30 \%$ decrease which was not statistically significant.

"One study (62) found a $23 \%$ decrease in abdominal rectus muscle but no change in vastus lateralis muscle.

$\rightarrow$ No change from control levels. 
translocation of GLUT4 in brown adipose cells (40) and in heart (19).

Glucose transporter functional activity. Under certain conditions, glucose transport in adipose cells $(35,36,41)$ and muscle (38) is not proportional to the measured number of glucose transporters in the plasma membrane. This has been proposed to reflect inadequate purification of subcellular membrane fractions so that transporter levels are falsely elevated in plasma membranes from cells in the basal state due to contamination with intracellular membranes which are highly enriched in transporters. However, such discrepancies have been observed even with labeling of transporters in intact cells using either an exofacial antibody (41) or an impermeant bis-mannose compound $(42,43)$. Kinetic studies confirm $V_{\max }$ effects which have been attributed to alterations in glucose transporter intrinsic activity (moles of glucose transported/transporter per unit time). Studies with the bis-mannose compound (42) extend earlier results (44) indicating that an activation step may be necessary for full stimulation of glucose transport by insulin (Fig. $1 \mathrm{~A}$ ). Furthermore, these studies suggest that GLUT4 transporters are constantly cycling between the plasma membrane and an intracellular pool in the presence of insulin (42, 43). The different activation states of GLUT4 may result from alterations in the accessibility of transporters to glucose as a result of altered configuration in the plasma membrane (S. Vannucci, personal communication).

Modulation of glucose transporter intrinsic activity appears important physiologically as it has been observed in adipose cells from rats refed after fasting (45) and from insulin-treated diabetic rats $(5,11)$. It is the major mechanism for reversal of insulin resistance in adipose cells of diabetic rats in which blood glucose is normalized using phlorizin (46), which blocks renal tubular reabsorption of glucose. Thus, changes in ambient glucose levels seem to alter the intrinsic activity of GLUT4 in adipose cells while insulin levels per se modulate GLUT4 expression (5). Modulation of GLUT4 intrinsic activity has also been demonstrated in skeletal muscle (38). The biochemical nature of this intrinsic activity change is unknown. One study suggests that sialic acid residues may play a role (47). Although studies have examined whether changes in the phosphorylation state of GLUT4 affects its intrinsic activity (48), the stoichiometry suggests that this is not the case.

Functional defects contribute to in vivo insulin resistance. Functional defects in transporters (Fig. $1 B$ ) appear particularly important in skeletal muscle in vivo. In spite of insulin-resistant glucose transport in both the insulinopenic and hyperinsulinemic states discussed above, levels of the major transporter GLUT4 are similar to control (Tables II and III) (18, 32-34, 49). This strongly supports the concept that circulating or local factors antagonize the function (including translocation) of glucose transporters in muscle under these in vivo conditions. This hypothesis stems from earlier studies (reviewed in 18) showing normal or increased insulin-stimulated glucose uptake in perfused hindlimb or isolated muscle from fasted $(50$, $51)$ and diabetic rats $(51,52)$ in spite of in vivo insulin resistance. Although other studies have demonstrated diminished insulin-stimulated glucose transport in muscle of diabetic rats, the defect reverses with incubation of the muscle in KrebsHenseleit bicarbonate buffer (53), again suggesting that circulating factors may inhibit glucose uptake in muscle in vivo. Although GLUT4 number has been reported to be decreased in some streptozotocin diabetic rat models (37), a functional defect precedes the fall in GLUT4 (18) and in hyperinsulinemic models, the functional defect appears to be most important $(32-34,49)$.

Such functional defects (Fig. $1 B$ ) may involve impaired translocation of transporters as suggested in a preliminary report in muscle of obese Zucker rats (54), "docking" of vesicles at the plasma membrane so that they are physically associated but not fused, partial fusion or altered configuration of transporters in the plasma membrane rendering them cryptic with inadequate exposure to the extracellular milieu, or reduced activation of transporters. The activation state of the transporter may be affected by factors extrinsic to the transporter such as the composition of associated membrane vesicles (55), characteristics of the cytoskeleton, or the presence of chaperone proteins affecting fusion of the vesicle with the plasma membrane and exposure to the extracellular milieu. Evidence is accumulating for the role of small molecular weight GTPases in vesicle translocation and membrane fusion (56) and a recent report demonstrated potential involvement of a GTPase in the translocation of GLUT4 in adipose cells (57).

\section{Dysregulation of glucose transporters in human diabetes}

Insulin-resistant glucose transport in peripheral tissues. Stimulation of glucose transport by insulin is markedly impaired in adipose cells from humans with non-insulin-dependent diabetes mellitus (NIDDM) $)^{1}(12)$ and this defect reverses with insulin treatment $(35,58)$. Recent evidence demonstrates a striking decrease in GLUT4 mRNA and protein levels in adipose cells from obese humans and an even greater reduction in obese NIDDM subjects (12, Table III). Interestingly, the GLUT4 mRNA levels in humans with impaired glucose tolerance but not overt diabetes are as low as those in NIDDM subjects, suggesting that pretranslational suppression of GLUT4 expression in adipose cells occurs very early in the development of the diabetic state. A study of morbidly obese subjects failed to detect an effect of obesity alone but showed a $65 \%$ decrease in GLUT4 levels in morbidly obese NIDDM subjects compared to lean controls (13).

However, in humans GLUT4 expression is subject to tissue-specific regulation as described above for insulin resistant animal models. The profound changes in GLUT4 expression in adipose cells are not observed in skeletal muscle (vastus lateralis) of obese nondiabetic subjects or lean or obese NIDDM subjects $(59,60)$ or in subjects with insulin-dependent diabetes mellitus (IDDM) (61) (Table III). One study (62) found a minimal decrease in GLUT4 in abdominal rectus muscle of morbidly obese subjects but the effect was much smaller than the impairment in glucose transport and was not present in vastus lateralis. Additionally, no significant differences in GLUT1 mRNA levels are observed in muscle of obese or diabetic subjects $(59,61)$. Since muscle is the tissue responsible for $\sim 80 \%$ of insulin mediated glucose disposal in vivo (63), the insulin-resistant glucose uptake characteristic of obesity and NIDDM cannot be attributed to altered expression of GLUT4 or GLUT1. Studies are in progress to determine whether impaired translocation, fusion with the plasma membrane or acti-

1. Abbreviations used in this paper: IDDM, insulin-dependent diabetes mellitus; NIDDM, non-insulin-dependent diabetes mellitus. 
vation of GLUT4 (Fig. 1) may be responsible for in vivo insulin-resistant glucose transport. Such defects may result from a more proximal lesion in the insulin signaling pathway.

It is possible to modulate GLUT4 levels in skeletal muscle of normal humans (22) and those with impaired glucose tolerance (Hughes, V. A., B. B. Kahn, P. R. Shepherd, D. Elahi, and W. J. Evans, unpublished data) by chronic exercise training. Exercise training also increases levels of GLUT4 mRNA and protein in muscle of normal rats (64) and obese Zucker rats (33). This could be part of the mechanism for the decreased incidence of NIDDM in high risk subjects who are physically active $(65,66)$. GLUT4 levels in skeletal muscle correlate with one index of insulin sensitivity based on oral glucose tolerance testing (22), and with maximally insulin-stimulated glucose disposal measured by euglycemic insulin clamp in young, healthy subjects (67).

Potential role for glucose transporters in impaired insulin secretion. One of the intriguing, well-established characteristics of the insulin secretory defect in NIDDM is its selectivity for glucose-stimulated insulin secretion with normal insulin secretion in response to other secretagogues. Recent studies suggest a potential role for GLUT2 as part of the "glucose sensing apparatus" to elicit insulin secretion. GLUT2 expression is decreased in $\beta$ cells from rats with experimental or spontaneous diabetes (28-30) but increased in rats made hyperglycemic by glucose infusion (68). One study showed a correlation between the level of GLUT2 expression and glucose transport in isolated islets (29). The potential role of GLUT2 in $\beta$ cells in the decreased insulin secretory response to glucose in both type I and type II diabetes has recently been reviewed (30). The field is complicated by evidence suggesting another low $K_{\mathrm{m}}$ glucose transporter in islets which is not GLUT1 or GLUT4 (69).

Potential role for glucose transporters in increased hepatic glucose production. The potential role of altered glucose transporter expression or function in the paradoxically increased hepatic glucose production characteristic of diabetes is unclear since glucose transport is not rate limiting for hepatic glucose metabolism. The increased rows of perivenous hepatocytes expressing GLUT1 in diabetic rats (9, see above) could affect gradients of glucose across the hepatic bed; the significance of this is speculative.

\section{Glucose transporter mutations in human disease}

One example of a human disease resulting from a genetic defect in a glucose transporter has been identified. Glucose/galactose malabsorption in an inbred Syrian family appears to result from a single missense mutation at base pair 92 of exon 1 of the $\mathrm{Na}^{+}$/glucose cotransporter (70). This mutation does not interfere with membrane assembly of the transporter when expressed in Xenopus oocytes but obliterates $\mathrm{Na}^{+}$-dependent transport of alpha-methyl-D-glucopyranoside, a specific substrate for the $\mathrm{Na}^{+}$/glucose cotransporter. Since this mutation is not present in other families with glucose/galactose malabsorption, heterogeneity of molecular defects must underlie this disease.

Since insulin-resistant glucose uptake in peripheral tissues is a hallmark of NIDDM and GLUT4 is the major transporter in these tissues, investigators have screened subjects with NIDDM for mutations in GLUT4 $(71,72)$. Only one mutation and one silent polymorphism have been found. A substitution of the amino acid isoleucine for valine at position 383 in exon 9 was present in one of 60 NIDDM subjects examined in one study (71) and 3 of 190 NIDDM subjects in another study (72). The functional significance of this mutation is not yet known. Importantly, it is uncommon and other mutations in the coding region of the GLUT4 gene are unlikely in the vast majority of cases of NIDDM (72). The impairment in insulin-stimulated glucose transport in NIDDM is probably due in part to hyperglycemia, since it is partially reversed with good glycemic control $(35,58)$ and it is also observed in IDDM and in animal models of insulin-deficient diabetes $(11,12,46)$ in which restoration of euglycemia without insulin therapy results in normalization of insulin-stimulated glucose transport and in vivo glucose disposal (46).

Recently, mutations in GLUT1 have been proposed in two children with seizures refractory to antiepileptic medication, hypoglycorrhachia (low cerebrospinal fluid glucose), and developmental delay (73). Presence of normal plasma glucose and cerebrospinal fluid lactate levels and resolution of seizures with a ketogenic diet suggested a reduction in glucose transport across the blood-brain barrier. Glucose transport and GLUT1 concentrations were reduced in erythrocytes which express high levels of GLUT1, the major transporter in the blood-brain barrier. Erythrocytes from one patient also showed markedly reduced immunoreactivity to a GLUT1 antibody, indicating a potential structural change in GLUT1 which could result from a mutation in the GLUT1 gene. Sequencing of the GLUT1 genes from these patients will determine whether a genetic defect is responsible for the disorder.

\section{Future directions}

The observations discussed above indicate that biological complexity has evolved to allow specific regulation of different glucose transporter isoforms in a tissue-specific manner and even in a regional manner within specific tissues. Alterations in expression of transporters may contribute to disease states such as diabetes, but changes in the function and subcellular distribution of transporters are also key (Fig. 2). Studies now need to focus on the cellular and molecular mechanisms which underlie: (a) tissue specific expression of transporters; $(b)$ targeting of

\section{Alterations in Glucose Transporters}

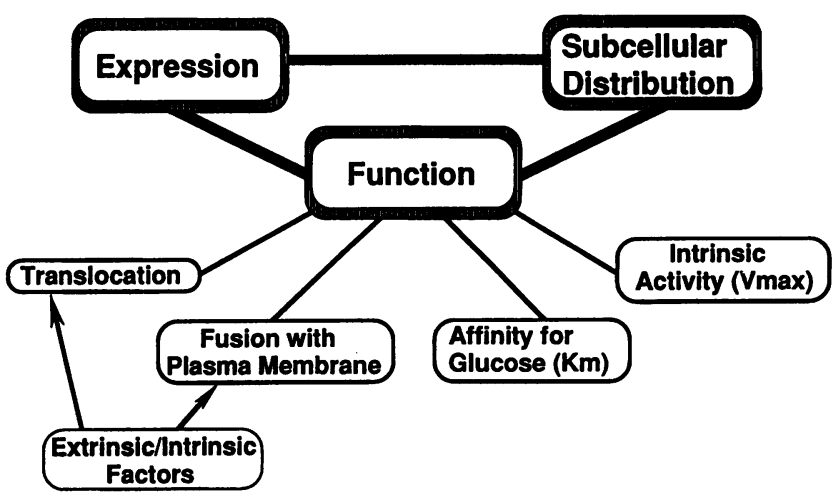

Figure 2. Mechanisms contributing to the insulin-resistant glucose transport characteristic of states such as obesity and diabetes. Insulin resistance results, in part, from alterations in glucose transporter expression, subcellular distribution, and various functional characteristics. 
transporters to different cellular compartments, as well as $(c)$ the key signaling pathways essential for transporter translocation, fusion with the plasma membrane, and activation. In insulin-responsive tissues, the signals which couple insulin binding to its receptor with stimulation of glucose transport need further elucidation. Such studies will lead to a deeper understanding of the pathogenesis of diabetes and potentially to new therapeutic approaches.

\section{Acknowledgments}

The author is deeply grateful to her colleagues for their contributions to the studies discussed here: O. Pedersen, M. J. Charron, L. Rossetti, J. S. Flier, S. W. Cushman, H. F. Lodish, B. Thorens, and M. Tal. She wishes to thank Drs. D. E. Moller, J. S. Flier, and A. C. Moses for helpful comments on the manuscript, Dr. P. R. Arvan for valuable discussions, and A. S. Rosen for technical assistance and for his expertise drawing the figures.

The author is the recipient of Physician Scientist Award \#AG00294 from the National Institute on Aging, Juvenile Diabetes Foundation Grants \#187487 and \#189833, and a Capps Scholar Award from Harvard Medical School.

\section{References}

1. Wright, E. W., E. Turk, B. Zabel, S. Mundios, and J. Dyer. 1991. Molecular genetics of intestinal glucose transport. J. Clin. Invest. 88:1435-1440.

2. Mueckler, M. 1990. Family of glucose-transporter genes. Implications for glucose homeostasis and diabetes. Diabetes. 39:6-11.

3. Bell, G. I., T. Kayano, J. B. Buse, C. F. Burant, J. Takeda, D. Lin, H. Fukumoto, and S. Seino. 1990. Molecular biology of mammalian glucose transporters. Diabetes Care. 13:198-208.

4. Thorens, B., M. J. Charron, and H. F. Lodish. 1990. Molecular physiology of glucose transporters. Diabetes Care. 13:209-218.

5. Kahn, B. B., and J. S. Flier. 1990. Regulation of glucose-transporter gene expression in vitro and in vivo. Diabetes Care. 13:548-564.

6. Gould, G. W., H. M. Thomas, T. J. Jess, and G. I. Bell. 1991. Expression of human glucose transporters in xenopus oocytes: kinetic characterization and substrate specificities of the erythrocyte, liver, and brain isoforms. Biochemistry. 30:5139-5145.

7. Keller, K., M. Strube, and M. Mueckler. 1989. Functional expression of the human HepG2 and rat adipocyte glucose transporters in xenopus oocytes. J. Biol. Chem. 32:18884-18889.

8. Thorens, B., H. F. Lodish, and D. Brown. 1990. Differential localization of two glucose transporter isoforms in rat kidney. Am. J. Physiol. 259 (Cell Physiol. 28):C286-C294.

9. Tal, M., B. B. Kahn, and H. F. Lodish. 1991. Expression of the low $K_{\mathrm{m}}$ GLUT1 glucose transporter is turned on in perivenous hepatocytes of insulin-deficient diabetic rats. Endocrinology. 129:1933-1941.

10. Garvey, T. W., T. P. Huecksteadt, and M. J. Birnbaum. 1989. Pretranslational suppression of an insulin-responsive glucose transporter in rats with diabetes mellitus. Science (Wash. DC). 245:60-63.

11. Kahn, B. B., M. J. Charron, H. F. Lodish, S. W. Cushman, and J. S. Flier. 1989. Differential regulation of two glucose transporters in adipose cells from diabetic and insulin-treated diabetic rats. J. Clin. Invest. 84:404-411.

12. Garvey, W. T., L. Maianu, T. P. Huecksteadt, M. J. Birnbaum, J. M. Molina, and T. P. Ciaraldi. 1991. Pretranslational suppression of a glucose transporter protein causes insulin resistance in adipocytes from patients with non-insulin-dependent diabetes mellitus and obesity. J. Clin. Invest. 87:1072-1081.

13. Sinha, M. K., C. Raineri-Maldonado, C. Buchanan, W. J. Pories, C. Carter-Su, P. F. Pilch, and J. O. Caro. 1991. Adipose tissue glucose transporters in NIDDM. Diabetes. 40:472-477.

14. Zorzano, A., W. Wilkinson, N. Kotliar, G. Thoidis, B. E. Wadzinski, A. E. Ruoho, and P. F. Pilch. 1989. Insulin-regulated glucose uptake in rat adipocytes is mediated by two transporter isoforms present in at least two vesicle populations. J. Biol. Chem. 264:12358-12363.

15. Oka, Y., T. Asano, Y. Shibaski, M. Kasuga, Y. Kanazawa, and F. Takaku. 1988. Studies with antipeptide antibody suggest the presence of at least two types of glucose transporter in rat brain and adipocyte. J. Biol. Chem. 263:1343213439.
16. Calderhead, D. M., K. Kitagawa, G. E. Lienhard, and G. W. Gould. 1990. Translocation of the brain-type glucose transporter largely accounts for insulin stimulation of glucose transport in BC3H-1 myocytes. Biochem. J. 269:597-601.

17. Froehner, S. C., A. Davies, S. A. Baldwin, and G. E. Lienhard. 1988. The blood-nerve barrier is rich in glucose transporter. J. Neurocytol. 17:173-178.

18. Kahn, B. B., L. Rossetti, H. F. Lodish, and M. J. Charron. 1991. Decreased in vivo glucose uptake but normal expression of GLUT1 and GLUT4 in skeletal muscle of diabetic rats. J. Clin. Invest. 87:2197-2206.

19. Slot, J. W., H. J. Geuze, S. Gigengack, D. E. James, and G. E. Lienard. 1991. Translocation of the glucose transporter GLUT4 in cardiac myocytes of the rat. Proc. Natl. Acad. Sci. USA. 88:7815-7819.

20. James, D. E., M. Strube, and M. Mueckler. 1989. Molecular cloning and characterization of an insulin-regulatable glucose transporter. Nature (Lond.). 338:83-87.

21. Henriksen, E. J., R. E. Bourey, K. J. Rodnick, L. Koranyi, and M. A. Permutt. 1990. Glucose transporter protein content and glucose transport capacity in rat skeletal muscles. Am. J. Physiol. 259 (Endocrinol. Metab. 22):E593E598.

22. Houmard, J. A., P. C. Egan, P. D. Neufer, J. E. Friedman, W. Wheeler, R. G. Israel, and G. L. Dohm. 1991. Elevated skeletal muscle glucose transporter levels in exercise-trained middle-aged man. Am. J. Physiol. 261:E437-E443.

23. Piper, R. C., L. J. Hess, and D. E. James. 1991. Differential sorting of two glucose transporters expressed in insulin-sensitive cells. Am. J. Physiol. 260:C570-C580.

24. Berger, J. C., C. Diswas, P. Vicario, H. V. Strout, R. Saperstein, and P. F. Pilch. 1989. Decreased expression of the insulin-responsive glucose transporter in diabetes and fasting. Nature (Lond.). 340:70-72.

25. Sivitz, W. I., S. L. DeSautel, T. Kayano, G. I. Bell, and J. E. Pessin. 1989. Regulation of glucose transporter messenger RNA in insulin-deficient states. $\mathrm{Na}$ ture (Lond.). 340:72-74.

26. Charron, M. J., and B. B. Kahn. 1990. Divergent molecular mechanisms for insulin resistant glucose transport in muscle and adipose cells in vivo. J. Biol. Chem. 265:7994-8000.

27. Thorens, B., J. S. Flier, H. F. Lodish, and B. B. Kahn. 1990. Expression of two glucose transporters in rat liver is differentially regulated by fasting and refeeding and by diabetes and insulin treatment. Diabetes. 39:712-719.

28. Thorens, B., G. C. Weir, J. L. Leahy, H. F. Lodish, and S. Bonner-Weir. 1990. Reduced expression of the liver/beta-cell glucose transporter isoform in glucose-insensitive pancreatic beta cells of diabetic rats. Proc. Natl. Acad. Sci. USA. 87:6492-6496.

29. Johnson, J. H., A. Ogawa, L. Chen, L. Orci, C. B. Newgard, T. Alam, and R. H. Unger. 1990. Underexpression of $\beta$ cell high $K_{\mathrm{m}}$ glucose transporters in non-insulin-dependent diabetes. Science (Wash. DC). 250:546-549.

30. Unger, R. H. 1991. Diabetic hyperglycemia: link to impaired glucose transport in pancreatic $\beta$ cells. Science (Wash. DC). 251:1200-1205.

31. Richardson, J. M., T. W. Balon, J. L. Treadway, and J. E. Pessin. 1991. Differential regulation of glucose transporter activity and expression in red and white skeletal muscle. J. Biol. Chem. 266:12690-12694.

32. Kahn, B. B., and O. Pedersen. 1991. Tissue specific regulation of glucose transporters in adipose cells and muscle of obese Zucker rats. In New Directions in Research and Clinical Works for Obesity and Diabetes Mellitus. N. Sakamoto, A. Angel, and N. Hotta, editors. Elsevier Science Publishers B. V., Amsterdam. 225-227.

33. Friedman, J. E., W. M. Sherman, M. J. Reed, C. W. Elton, and G. L. Dohm. 1990. Exercise training increases glucose transporter protein GLUT4 in skeletal muscle of obese Zucker (fa/fa) rats. FEBS (Fed. Eur. Biochem. Soc.) Lett. 268:13-16.

34. Hainault, M., M. Guerre-Millo, C. Guichard, and M. Lavau. 1991. Differential regulation of adipose tissue glucose transporters in genetic obesity (fatty rat). J. Clin. Invest. 87:1127-1131.

35. Kahn, B. B., and S. W. Cushman. 1985. Subcellular translocation of glucose transporters: role in insulin action and its perturbation in altered metabolic states. Diabetes Metab. Rev. 1:203-227.

36. Simpson, I. A., and S. W. Cushman. 1989. Hormonal regulation of mammalian glucose transport. Annu. Rev. Biochem. 55:1059-1089.

37. Klip, A. 1991. Acute and chronic signals controlling glucose transport in skeletal muscle. J. Cell. Biochem. 48:51-60.

38. Goodyear, L. J. 1992. Effects of insulin and exercise on the glucose transport system in skeletal muscle. In Diabetes Mellitus and Exercise. J. T. Devlin, editor. Smith Gordon, London. In press.

39. Biber, J. W., and G. E. Lienhard. 1986. Isolation of vesicles containing insulin-responsive, intracellular glucose transporters from 3T3-L1 adipocytes. $J$. Biol. Chem. 261:16180-16184.

40. Slot, J. W., H. J. Geuze, S. Gigengack, G. E. Lienhard, and D. E. James. 1991. Immuno-localization of the insulin regulatable glucose transporter in brown adipose tissue of the rat. J. Cell Biol. 113:123-135.

41. Harrison, S. A., J. M. Buxton, and M. P. Czech. 1991. Suppressed intrinsic catalytic activity of GLUT1 glucose transporters insulin-sensitive 3T3-L1 adipocytes. Proc. Natl. Acad. Sci. USA. 88:7839-7843. 
42. Clark, A. E., G. D. Holman, and I. J. Kozka. 1991. Determination of the rates of appearance and loss of glucose transporters at the cell surface of rat adipose cells. Biochem. J. 278:235-241.

43. Satoh, S., O. M. Gonzalez-Mulero, A. E. Clark, I. J. Kozka, G. D. Holman, and S. W. Cushman. 1991. Recycling of cell surface GLUT4 glucose transporters in rat adipose cells photolabeled in the insulin-stimulated state. Diabetes. 40:85A.

44. Karnieli, E., M. J. Zarnowski, P. J. Hissin, I. A. Simpson, L. B. Salans, and S. W. Cushman. 1981. Insulin-stimulated translocation of glucose transport systems in the rat adipose cell: time course, reversal, insulin concentration-dependency and relationship to glucose transport activity. J. Biol. Chem. 256:47724777 .

45. Kahn, B. B., I. A. Simpson, and S. W. Cushman. 1988. Divergent mechanisms for the insulin resistant and hyperresponsive glucose transport in adipose cells from fasted and refed rats: alterations in both glucose transporter number and intrinsic activity. J. Clin. Invest. 82:691-699.

46. Kahn, B. B., G. I. Shulman, R. A. DeFronzo, S. W. Cushman, and L. Rossetti. 1991. Normalization of blood glucose in diabetic rats with phlorizin treatment reverses insulin resistant glucose transport in adipose cells without restoring glucose transporter gene expression. J. Clin. Invest. 87:561-570.

47. Ciaraldi, T. P. 1989. Neuraminidase treatment of isolated rat adipocytes and differential regulation of basal and insulin-stimulated glucose transport. Diabetes. 38:951-958.

48. James, D. E., J. Hiken, and J. C. Lawrence. 1989. Isoproterenol stimulates phosphorylation of the insulin-regulatable glucose transporter in rat adipocytes. Proc. Natl. Acad. Sci. USA. 86:8368-8372.

49. Koranyi, L., D. James, M. Mueckler, and M. A. Permutt. 1990. Glucose transporter levels in spontaneously obese $(\mathrm{db} / \mathrm{db})$ insulin-resistant mice. J. Clin. Invest. 85:962-967.

50. Goodman, M. N., M. Berger, and N. B. Ruderman. 1974. Glucose metabolism in rat skeletal muscle at rest: effect of starvation, diabetes, ketone bodies and free fatty acids. Diabetes. 23:881-888.

51. Le Marchand-Brustel, Y., and P. Freychet. 1979. Effect of fasting and streptozotocin diabetes on insulin binding and action in the isolated mouse soleus muscle. J. Clin. Invest. 64:1505-1515.

52. Chiasson, J. L., L. Germain, A. K. Stivastava, and P. Dupuis. 1984. Hormonal regulation of glucose transport in contracting skeletal muscle from normal and diabetic rats. Metab. Clin. Exp. 33:617-621.

53. Wallberg-Henriksson, H., N. Zetan, and J. Henriksson. 1987. Reversibility of decreased insulin-stimulated glucose transport capacity in diabetic muscle with in vitro incubation. J. Biol. Chem. 262:7665-7671.

54. Horton, E. D., P. A. King, M. F. Hirshman, and E. S. Horton. 1990. Failure of insulin to stimulate glucose transporter translocation in skeletal muscle from the obese $(\mathrm{fa} / \mathrm{fa})$ zucker rat. Diabetes. 39:83 $\mathrm{A}$.

55. Clandinin, M. T., S. Cheema, C. J. Field, M. L. Garg, J. Venkatraman, and T. R. Clandinin. 1991. Dietary fat: exogenous determination of membrane structure and cell function. FASEB (Fed. Am. Soc. Exp. Biol.) J. 5:2761-2769.

56. Balch, W. E. 1990. Small GTP-binding proteins in vesicular transport. Trends Biochem. Sci. 16:473-477.

57. Baldini, G., R. Hohman, M. J. Charron, and H. F. Lodish. 1991. Insulin and nonhydrolyzable GTP analogues induce translocation of GLUT4 to the plasma membrane in alpha-toxin-permeabilized rat adipose cells. J. Biol. Chem. 266:4037-4040.

58. Scarlett, J. A., O. G. Kolterman, T. P. Ciaraldi, M. Kao, and J. M. Olefsky. 1983. Insulin treatment reverses the post receptor defect in adipocyte 3-0 methylglucose transport in type II diabetes mellitus. J. Clin. Endocrinol. \& Metab. 56:1195-1201.

59. Pedersen, O., J. F. Bak, P. H. Andersen, S. Lund, D. E. Moller, J. S. Flier, and B. B. Kahn. 1990. Evidence against altered expression of GLUT1 or GLUT4 in skeletal muscle of patients with obesity of NIDDM. Diabetes. 39:865-870.
60. Handberg, A., A. Vaag, P. Damsbo, H. Beck-Nielsen, and J. Vinten. 1990. Expression of insulin regulatable glucose transporters in skeletal muscle from type 2 (non-insulin-dependent) diabetic patients. Diabetologia. 33:625-627.

61. Kahn, B. B., A. S. Rosen, J. F. Bak, P. H. Andersen, S. Lund, and O. Pedersen. 1992. Expression of GLUT1 and GLUT4 glucose transporters in skeletal muscle of humans with insulin-dependent diabetes mellitus: regulatory effects of metabolic factors. J. Clin. Endocrinol. \& Metab. 74:1101-1109.

62. Dohm, G. L., C. W. Elton, J. E. Friedman, P. F. Pilch, W. J. Pories, S. M. Atkinson, Jr., and J. F. Caro. 1990. Decreased expression of glucose transporter in muscle from insulin-resistant patients. Am. J. Physiol. 260:E459-E463.

63. DeFronzo, R. A., E. Jacto, E. Jequier, E. Maeder, J. Wahren, and J. P. Felber. 1981. The effect of insulin on the disposal of intravenous glucose. Diabetes. 30:1000-1007.

64. Ploug, T., B. M. Stallknecht, O. Pedersen, B. B. Kahn, T. Ohkuwa, J. Vinten, and H. Galbo. 1990. The effect of endurance training on glucose transport capacity and expression of glucose transporters in rat skeletal muscle. Am. J. Physiol. 259:E778-E786.

65. Helmrich, S. P., D. R. Ragland, R. W. Leung, and R. S. Paffenbarger, Jr. 1991. Physical activity and reduced occurrence of non-insulin-dependent diabetes mellitus. $N$. Engl. J. Med. 325:147-152.

66. Manson, J. E., E. B. Rimm, M. J. Stampfer, G. A. Colditz, W. C. Willett, A. S. Krolewski, B. Rosner, C. H. Hennekens, and F. E. Speizer. 1991. Physical activity and incidence of non-insulin-dependent diabetes mellitus in women. Lancet. 338:774-778.

67. Koranyi, L. I., R. E. Bourey, H. Vuorinen-Markkola, V. A. Koivisto, M. Mueckler, M. A. Permutt, and H. Yki-Jarvinen. 1991. Levels of skeletal muscle glucose transporter protein correlates with insulin-stimulated whole body glucose disposal in man. Diabetologia. 34:763-765.

68. Chen, L., T. Alam, J. H. Johnson, S. Hughes, C. B. Newgard, and R. H. Unger. 1990. Regulation of $\beta$-cell glucose transporter gene expression. Proc. Natl. Acad. Sci. USA. 87:4088-4092.

69. Johnson, J. H., C. B. Newgard, J. J. Milburn, H. F. Lodish, and B. Thorens. 1990. The high $K_{\mathrm{m}}$ glucose transporter of islets of Langerhans is functionally similar to the low affinity transporter of liver and has an identical primary sequence. J. Biol. Chem. 265:6548-6551.

70. Turk, E., B. Zabel, S. Mundlos, J. Dyer, and E. M. Wright. 1991. Glucose/ galactose malabsorption caused by a defect in the $\mathrm{Na}^{+} /$glucose cotransporter. Nature (Lond.). 350:354-356.

71. Kusari, J., U. S. Verma, J. B. Buse, R. R. Henry, and J. M. Olefsky. 1991. Analysis of the gene sequences of the insulin receptor and the insulin-sensitive glucose transporter (GLUT4) in patients with common-type non-insulin-dependent diabetes mellitus. J. Clin. Invest. 88:1323-1330.

72. Choi, W. H., S. O'Rahilly, A. Rees, R. Morgan, J. S. Flier, and D. E. Moller. 1991. Molecular scanning of the insulin-responsive glucose transporter (GLUT4) gene in patients with non-insulin dependent diabetes mellitus. Diabetes. 40:1712-1718.

73. De Vivoi, D. C., R. R. Trifiletti, R. I. Jacobson, G. M. Ronen, R. A. Behmand, and S. I. Harik. 1991. Defective glucose transport across the bloodbrain barrier as a cause of persistent hypoglycorrhacia, seizures, and developmental delay. N. Engl. J. Med. 325:703-709.

74. Pedersen, O., C. R. Kahn, J. S. Flier, B. B. Kahn. 1991. High fat feeding causes insulin resistance and a marked decrease in the expression of glucose transporters (Glut4) in fat cells of rats. Endocrinology. 129:771-777.

75. Kahn, B. B., E. S. Horton, and S. W. Cushman. 1987. Mechanism for enhanced glucose transport response to insulin in adipose cells from chronically hyperinsulinemic rats: increased translocation of glucose transporters from an enlarged intracellular pool. J. Clin. Invest. 79:853-858.

76. Hirshman, M. F., L. J. Wardzala, L. J. Goodyear, S. P. Fuller, E. D. Horton, and E. S. Horton. 1989. Exercise training increases the number of glucose transporters in rat adipose cells. Am. J. Physiol. 257:E520-530. 